Article

\title{
Spectral Discrimination of Vegetation Classes in Ice-Free Areas of Antarctica
}

\author{
María Calviño-Cancela ${ }^{1, *}$ and Julio Martín-Herrero ${ }^{2}$ \\ 1 Department of Ecology and Animal Biology, University of Vigo, School of Sciences, \\ Campus Lagoas-Marcosende, Vigo 36310, Spain \\ 2 Department of Signal Theory and Communications, University of Vigo, AtlantTIC Research Center, \\ Vigo 36310, Spain; julio@uvigo.es \\ * Correspondence: maria@uvigo.es; Tel.: +34-986-818-742 \\ Academic Editors: Yuei-An Liou, Chyi-Tyi Lee, Yuriy Kuleshov, Jean-Pierre Barriot, Chung-Ru Ho, \\ Randolph H. Wynne and Prasad S. Thenkabail \\ Received: 4 July 2016; Accepted: 11 October 2016; Published: 18 October 2016
}

\begin{abstract}
Detailed monitoring of vegetation changes in ice-free areas of Antarctica is crucial to determine the effects of climate warming and increasing human presence in this vulnerable ecosystem. Remote sensing techniques are especially suitable in this distant and rough environment, with high spectral and spatial resolutions needed owing to the patchiness and similarity between vegetation elements. We analyze the reflectance spectra of the most representative vegetation elements in ice-free areas of Antarctica to assess the potential for discrimination. This research is aimed as a basis for future aircraft/satellite research for long-term vegetation monitoring. The study was conducted in the Barton Peninsula, King George Island. The reflectance of ground patches of different types of vegetation or bare ground (c. $0.25 \mathrm{~m}^{2}, n=30$ patches per class) was recorded with a spectrophotometer measuring between $340 \mathrm{~nm}$ to $1025 \mathrm{~nm}$ at a resolution of $0.38 \mathrm{~nm}$. We used Linear Discriminant Analysis (LDA) to classify the cover classes according to reflectance spectra, after reduction of the number of bands using Principal Component Analysis (PCA). The first five principal components explained an accumulated $99.4 \%$ of the total variance and were added to the discriminant function. The LDA classification resulted in c. $92 \%$ of cases correctly classified (a hit ratio 11.9 times greater than chance). The most important region for discrimination was the visible and near ultraviolet (UV), with the relative importance of spectral bands steeply decreasing in the Near Infra-Red (NIR) region. Our study shows the feasibility of discriminating among representative taxa of Antarctic vegetation using their spectral patterns in the near UV, visible and NIR. The results are encouraging for hyperspectral vegetation mapping in Antarctica, which could greatly facilitate monitoring vegetation changes in response to a changing environment, reducing the costs and environmental impacts of field surveys.
\end{abstract}

Keywords: Antarctica; classification; field spectroscopy; hyperspectral imaging; species discrimination; lichen; moss; Deschampsia antarctica

\section{Introduction}

Antarctic terrestrial ecosystems are changing rapidly in response to global threats, such as climate warming [1] and the introduction of alien species [2,3], and to local impacts due to increasing human presence [4]. The Maritime Antarctica has experienced rapid warming over the past 50 years, and additional, more accelerated warming is predicted for the future [1,5]. Increasing temperatures result in the recession of glaciers and snow, exposing new bare ground for colonization by pioneer vegetation [6,7]. They also involve longer summer-growing seasons and higher water availability, thus ameliorating the harsh conditions prevailing in Antarctica. This leads to an increase in the 
abundance and diversity of lichens and bryophytes, the most dominant in Antarctic terrestrial ecosystems, and to the expansion of flowering plants [8,9]. Colonization and expansion of alien species is also favoured, owing to this amelioration of environmental constraints and the increase in dispersal mediated by humans [10]. Increasing competition may lead also to the loss of some native species. Thus, changes in both structure and floristic composition of communities are expected in the short-, medium- and long-term timescales [11].

The Antarctic Peninsula and adjacent islands are considered an important indicator of global climate change $[5,12]$ due to the extraordinary rates of environmental change in recent decades and the sensitivity of Antarctic terrestrial ecosystems [13,14]. Changes in vegetation can be used as indicators of these environmental changes $[15,16]$. Different communities characterize the successional stages of vegetation colonization after glacier and snow recession. These are indicative of the age of the terrain and of some environmental factors with important effects on vegetation development [6,17].

Detailed information on the vegetation in Antarctica is scarce and very patchy, with information being concentrated mostly on areas more frequently visited by researchers, such as the surroundings of research stations. However, for a detailed account of current and expected environmental changes, an extensive and long-term monitoring is needed in this globally important region. The remoteness, inaccessibility and rugged terrain that characterizes Antarctica makes traditional field methods impractical. In order to survey large areas, field surveys require substantial costs in labor and many observers. The movement of researchers in the field results in damage to the especially sensitive Antarctic environment. Remote sensing methods, in contrast, represent a cost-effective and reliable alternative, especially suitable for the task. Remote sensing techniques facilitate data acquisition in difficult access areas and allow the survey of a broad area simultaneously, which reduces the perturbations derived from multiple observers. The data obtained can be easily integrated into a geographic information system (GIS) for further analysis. In addition, acquired images constitute a permanent record of the status of the area, which can be useful in the future to analyze dynamics and processes not foreseen in the moment of acquisition.

Optical remote sensing usually involves the acquisition and analysis of reflectance spectra of terrain elements (such as mosses, lichens or bare ground). Reflectance spectral patterns are defined by the relative amount of light that is absorbed or reflected at different wavelengths by different target materials, which depends on their biochemical and structural properties. Instruments differ mainly in spatial and spectral resolution, spectral range, and the number of spectral bands where reflectance is measured. The patchy nature of Antarctic tundra, where inconspicuous lichens and mosses are interspersed with bare ground or snow (see Figure 1), and the similarity between species call for high spectral and spatial resolutions. Hyperspectral remote sensing, in which light reflectance is measured in many narrow, adjacent spectral bands (often $>100$ bands) appears as one of the most suitable techniques for the study of Antarctic vegetation [18-21].

Studies aimed at mapping vegetation in Antarctica using remote sensing techniques are scarce. Fretwell et al. [22] used the Normalized Difference Vegetation Index (NDVI) computed from Landsat images at $30 \mathrm{~m}$ spatial resolution. However, as the authors recognize in a recent work [23], the NDVI may overlook the presence of lichens even if they are abundant [24], and thus might seriously underestimate vegetation cover in Antarctica, where lichens are often dominant. Vieira et al. [17] used supervised classification to map Usnea sp. lichen communities in high-resolution QuickBird imagery (DigitalGlobe). Usnea can be used as a proxy for areas with less snow during the cold season, important for the understanding of periglacial processes in the region. Shin et al. [25] used linear unmixing of three endmember spectra (snow, rock/soil, and vegetation) extracted from Quickbird and KOMPSAT-2 imagery to map vegetation in Barton Peninsula. Casanovas et al. [23] mapped lichen cover in areas of the Antarctic Peninsula by means of a matched filter using three endmember spectra recorded in the field, but working with images of very poor spectral resolution (Landsat 7 and 8) compared to the field spectral measurements. They also compared the detection results with those from using NDVI. They normalized the spectra following the method described by Zhang et al. [26], devised to erase any 
differences among lichen spectra. The original purpose of [26] was to indistinctly detect lichens on rocks in the Short Wave Infra-Red (SWIR) region of the spectrum, to avoid interference by lichens on mineralogical studies.

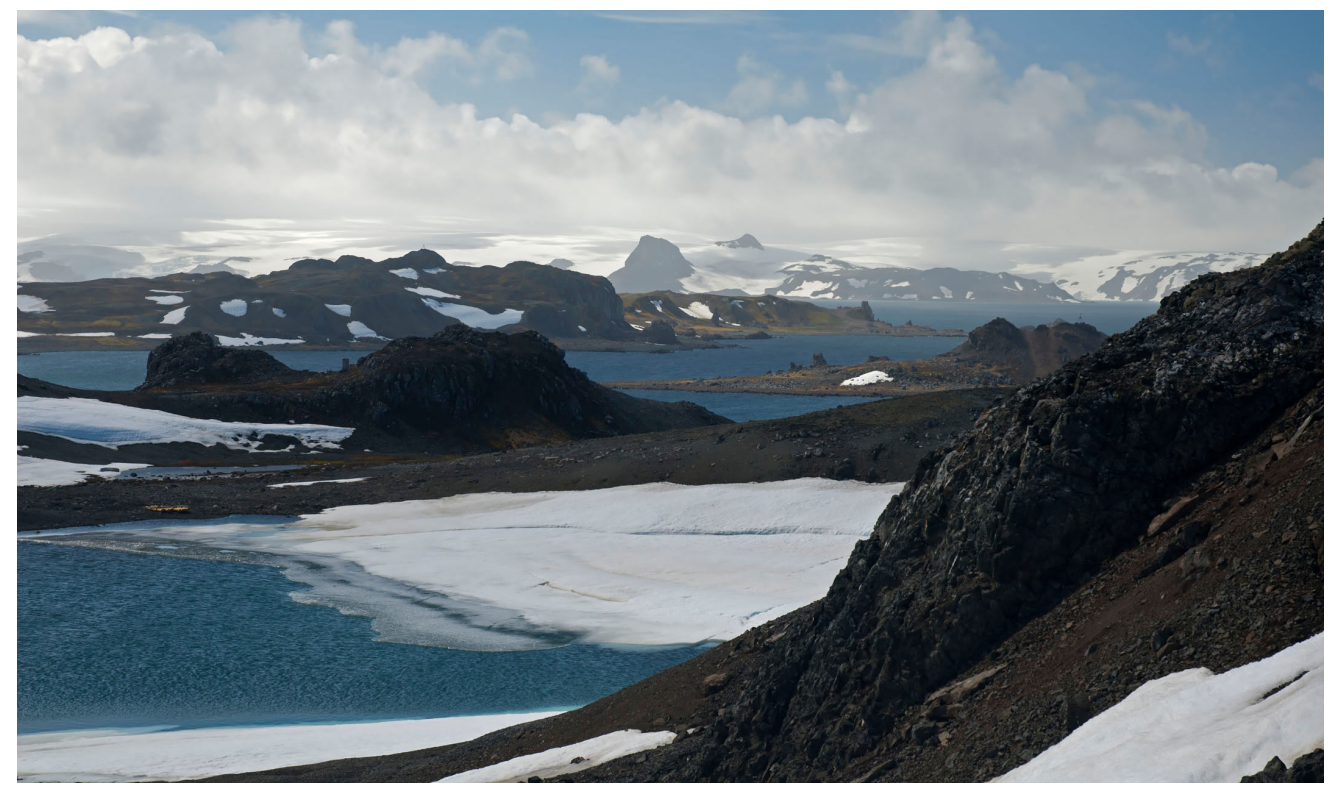

Figure 1. Typical ice-free Maritime Antarctic landscape. Rugged terrain with abrupt topography and an abundance of bare, highly dynamic ground, spotted with inconspicuous, heavily mixed vegetation (mainly lichens and mosses), most of the year covered by snow. High spatial and spectral resolutions are needed for accurate monitoring of vegetation in these regions.

It seems no attempt has been made yet to discriminate among the main different vegetation taxa in the region, including different taxa of lichens and moss. However, efficient techniques to map the distribution of different species and communities are necessary in order to facilitate spatially explicit conservation planning [27], which is highly needed in the region [28]. Spatial information about the distribution of vegetation is also essential for monitoring the effects of environmental changes and human impacts in the tundra and to follow their changes through time, e.g., the evolution of moss and lichen patterns on the surface as permafrost recedes [29]. For this, knowledge of the spectral characteristics of the most representative species of vegetation communities is required. Portable field spectrometers allow collecting in situ hyperspectral reflectance spectra of living vegetation. These spectroscopic measurements are required for upscaling. Upscaling allows the simulation and development of airborne or spatial instrumentation [30] with spatial, spectral and radiometric characteristics capable of tackling the discrimination problem at large scales [31]. Given the patchy nature of the Antarctic vegetation, a pixel in one of these images will often include a mixture of several terrain elements [25], so that the resulting reflectance spectrum is the average of those elements weighted by the area they cover. Endmember or spectral unmixing analysis can then be used to infer the presence and coverage of each of the elements [32,33]. However, first, the separability of the pure endmember spectra must be established or assumed, as it is a necessary condition for spectral unmixing and abundance estimation.

In this study, we analyze the reflectance spectra of the most representative taxa of Antarctic vegetation in ice-free areas in the Barton Peninsula, King George Island, in order to assess the potential for discrimination among them. This research is aimed as a basis for future aircraft/satellite research for developing long-term detailed monitoring of terrestrial vegetation to study the effect of environmental changes on the Antarctic tundra. 


\section{Methods}

\subsection{Study Area}

The data collection was conducted in January 2014 in the Barton Peninsula $\left(62^{\circ} 13^{\prime} \mathrm{S} 58^{\circ} 45^{\prime} \mathrm{W}\right)$, located in the SW of King George Island, where the Korean Antarctic Scientific Station King Sejong is located. King George Island is the largest island in the South Shetlands archipelago (Maritime Antarctic).

Due to a strong maritime effect, the climate on this island is humid and relatively mild compared to the Antarctic Peninsula. The average annual temperature is $-1.8^{\circ} \mathrm{C}$ and the average summer (December-February) temperature is $1.6^{\circ} \mathrm{C}$, according to the meteorological records collected in King Sejong Station since 1988. Relative humidity averages $89 \%$, with an average annual precipitation of $437 \mathrm{~mm}[34,35]$.

The typical ice-free Maritime Antarctic landscape (see photograph in Figure 1) is characterized by an abrupt topography, with most of the surface covered by glaciers, except for a narrow fringe along the coast. These ice-free areas are covered by abundant vegetation dominated by cryptogamic species, mostly lichens but also mosses and algae, with vascular plants being scarce but expanding in some areas [36,37].

\subsection{Field Spectral Measurements}

Reflectance, $\rho(\lambda)$, is the ratio of the spectral radiance of the surface, $L(\lambda)$, in $\mathrm{W} \cdot \mathrm{m}^{-2} \cdot \mathrm{sr}^{-1} \cdot \mu \mathrm{m}^{-1}$, to spectral solar irradiance, $E_{\mathrm{S}}(\lambda)$, in $\mathrm{W} \cdot \mathrm{m}^{-2} \cdot \mu \mathrm{m}^{-1}, \rho(\lambda)=\pi L(\lambda) /\left(E_{\mathrm{S}}(\lambda) \cos \left(\theta_{\mathrm{S}}\right)\right)$, with $\theta_{\mathrm{S}}$ the solar zenith angle. We recorded the reflectance of ground patches covered by different types of vegetation or bare ground with a dual-channel spectrophotometer (Ocean Optics USB2000, Dunedin, Florida, USA) covering the spectrum from $340 \mathrm{~nm}$ to $1025 \mathrm{~nm}$ with a spectral resolution of $0.38 \mathrm{~nm}$. Calibration was performed by means of a Tungsten halogen National Institute of Standards and Technology (NIST) traceable calibrated reference lamp (Ocean Optics LS-1-CAL) for irradiance calibration, and a $\mathrm{Hg}-\mathrm{Ar}$ reference lamp (Ocean Optics HG-1 253-922 nm) for wavelength calibration. One channel was devoted to measuring downwelling, i.e., the incidental radiation, by means of an upward-looking cosine corrector integrating $2 \pi \mathrm{sr}$. The other channel was pointed down to record the upwelling, i.e., the ground-reflected radiation. Upwelling and downwelling were simultaneously measured immediately after recording dark noise in both channels for each sample.

Fibre aperture and distance to the ground were selected to cover a c. $0.25 \mathrm{~m}^{2}$ plot on the ground. We selected homogeneous target areas dominated by each of the target cover classes, with $\geq 90 \%$ cover of the target class (estimated at centimeter scale with a $1 \mathrm{~cm}$ mesh trellis), and 30 patches per class. A total of 390 reflectance spectra of 13 different classes were measured in the field (see Table 1 and Figure 2); vegetation taxa are referred by the genus name in the text. Each measurement was recorded as the average of 40 sequential scans, in order to minimize instrument noise.

Wavelengths below $380 \mathrm{~nm}$ and above $1000 \mathrm{~nm}$ were eliminated to avoid the noise observed in the ends of the spectrum, due to the low signal-to-noise ratio caused by the poor sensitivity of the silicon detector at the extreme wavelengths. The bands between $760 \mathrm{~nm}$ and $775 \mathrm{~nm}$ were also eliminated due to high noise levels in this region, which we attribute to the effect of the $760 \mathrm{~nm}$ oxygen absorption band, heavily dependent on cloud coverage [38], abundant in Maritime Antarctica. Box averaging of five spectral samples was also performed for the final record to better approximate the typical spectral resolutions of hyperspectral remote sensing sensors.

We used a custom-built rig for the spectral measurements in the field, made with lightweight aircraft-grade aluminum alloy and black polyethylene. A vertical $2 \mathrm{~m}$ long pole supported a horizontal $1.5 \mathrm{~m}$ long beam with precision-machined sockets for the measuring optical fiber ends. The horizontal beam also supported a GPS receiver and its antenna, a nine-axis Inertial Measurement Unit (IMU) continuously measuring the attitude of the rig at $100 \mathrm{~Hz}$, and a nadir-looking, USB-controlled RGB camera with a fore lens matching the size and position of the terrain patch integrated by the upwelling 
fiber at the distance set by the vertical pole. The vertical pole also had a holder attached for the spectrophotometer and a shadowed stand for a ruggedized laptop computer, plus routing clips for all the wiring and optical fibers.

Table 1. Terrain cover classes whose spectra were recorded. Description information taken from [36,39-41]. Scientific names are according to [39] for lichens, [40] for mosses, and [36] for the vascular plant and alga.

\begin{tabular}{|c|c|}
\hline Class & Brief Description \\
\hline Bare ground & $\begin{array}{l}\text { Ground with no macroscopic forms of vegetation. Soils in the Barton Peninsula are } \\
\text { generally poor in organic material and nutrients and mostly composed of mineral } \\
\text { and rock fragments derived from the bedrock and volcanic ashes. Samples were } \\
\text { taken in basaltic andesite areas. }\end{array}$ \\
\hline \multicolumn{2}{|l|}{ Lichens } \\
\hline Aff. Lecanora polytropa & Crustose growth form with aerolate thallus, common on rocks frequented by birds. \\
\hline Stereocaulon sp. & $\begin{array}{l}\text { Fruticose growth form with photobiont trebouxioid and cephalodia } \\
\text { containing cyanobacteria. }\end{array}$ \\
\hline Psoroma sp. & $\begin{array}{l}\text { Squamulose growth form with photobiont Myrmecia and cephalodia containing } \\
\text { Nostoc. Frequently growing on mosses. }\end{array}$ \\
\hline Himantormia lugubris & Fruticose growth form and a trebouxioid photobiont. Endemic to Antarctica. \\
\hline Ramalina aff. tenebrata & $\begin{array}{l}\text { Fruticose growth form containing usnic acid. Widespread on coastal cliffs and large } \\
\text { boulders frequently associated with bird colonies (ornithocoprohillous). }\end{array}$ \\
\hline Usnea antarctica & $\begin{array}{l}\text { Fruticose lichen with probably the widest ecological amplitude of any Antarctic } \\
\text { lichen. Abundant in most habitats from sheltered to very exposed and moist to } \\
\text { dry situations. It forms dense stands on pebbles and gravels. Common and locally } \\
\text { abundant on mosses. }\end{array}$ \\
\hline Xanthoria sp. & $\begin{array}{l}\text { Foliose growth form rich in anthraquinone pigment giving its characteristic orange } \\
\text { colour. Abundant on rocks influenced by birds. }\end{array}$ \\
\hline Sphaerophorus globosus & Fruticose lichen growing in coralloid tufts to $10 \mathrm{~cm}$ tall. Photobiont trebouxioid. \\
\hline \multicolumn{2}{|l|}{ Mosses } \\
\hline Sanionia uncinata & $\begin{array}{l}\text { Mat forming moss with a wide geographic distribution and growing in a variety } \\
\text { of substrata. }\end{array}$ \\
\hline Andreaea sp. & $\begin{array}{l}\text { Pioneer moss in exposed rocks and fellfields. The spectra recorded correspond to } \\
\text { mixtures of rocks (basaltic andesite) and Andreaea mosses, both alive and dead. }\end{array}$ \\
\hline \multicolumn{2}{|l|}{ Alga } \\
\hline Prasiola crispa & $\begin{array}{l}\text { Nitrophilous alga that forms dense mats in wet areas very high in nutrients in } \\
\text { penguin colonies. }\end{array}$ \\
\hline \multicolumn{2}{|l|}{ Vascular plant } \\
\hline Deschampsia antarctica & $\begin{array}{l}\text { One of the two flowering plants native to Antarctica. Cushion-forming perennial } \\
\text { grass with thin leaves. }\end{array}$ \\
\hline
\end{tabular}

With the pole held in vertical position and its base resting on the ground, the distance from the upwelling fiber tip to the ground was held constant and thus also the size of the terrain patch integrated by the fiber aperture. A proper vertical position of the pole also guaranteed proper downwelling irradiance integration by the cosine corrector at the tip of the downwelling fiber. A custom software application running on the computer centralized all sensor data to ensure standard spectral measurement conditions. The GPS provided location and precise time data, which together with rig orientation and attitude data from the IMU allowed taking the spectral measurements always with the correct upright pole position and constant orientation with respect to the source, the Sun, even when covered by clouds. A graphical display on the computer's touchscreen showed the deviation from the 
upright position and ideal azimuth, and indicated by means of a semaphoric color code whether the rig was held at the right orientation and attitude to get adequate spectral measurements.

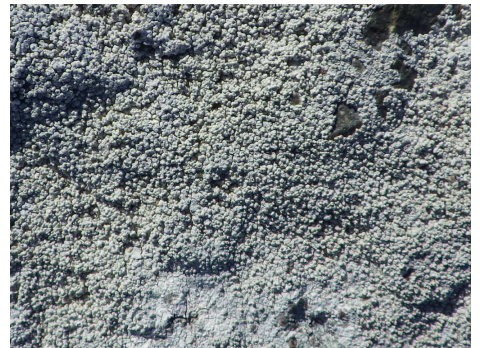

(a)

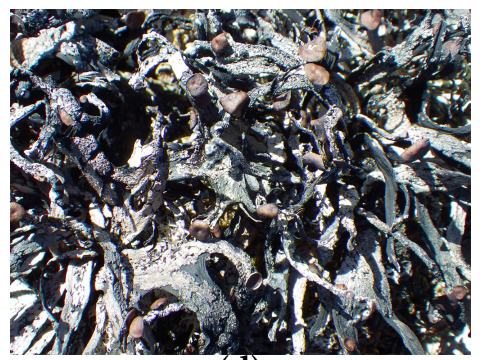

(d)

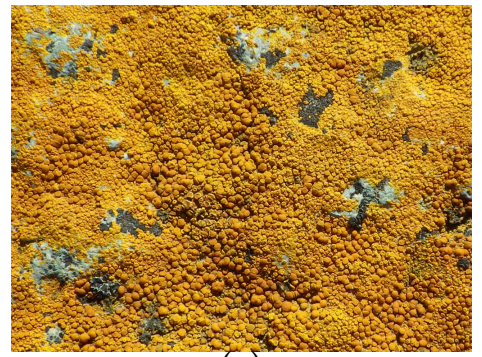

(g)

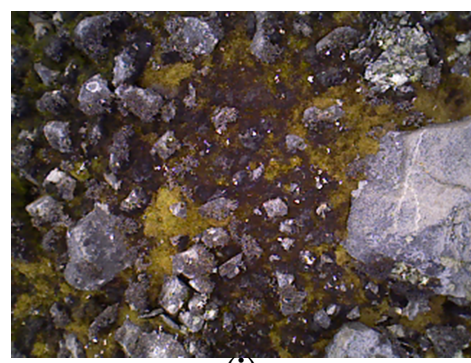

(j)

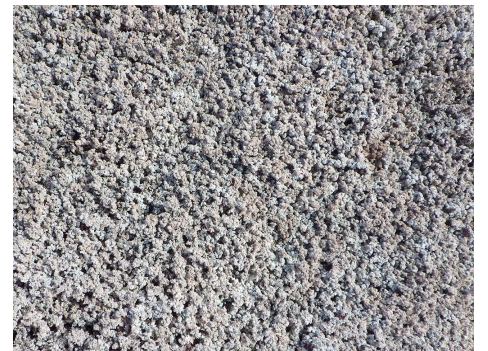

(b)

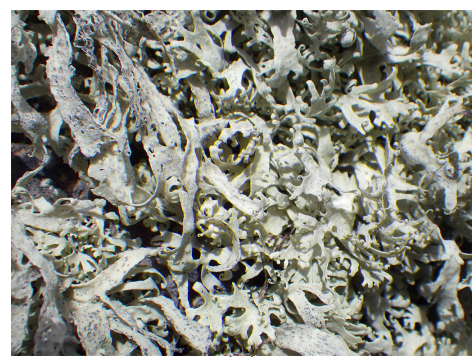

(e)



(h)

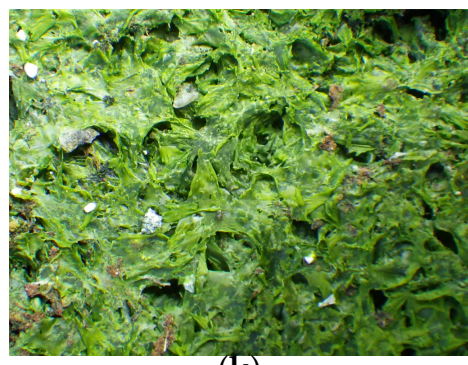

(k)

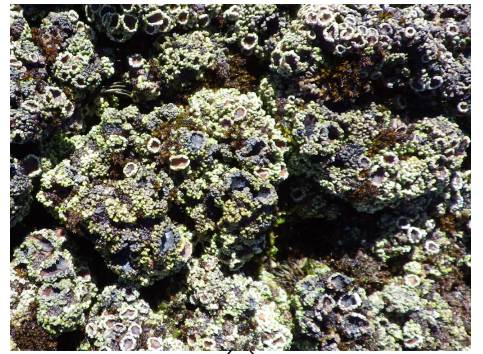

(c)

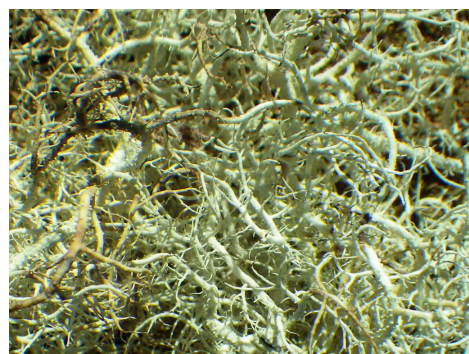

(f)

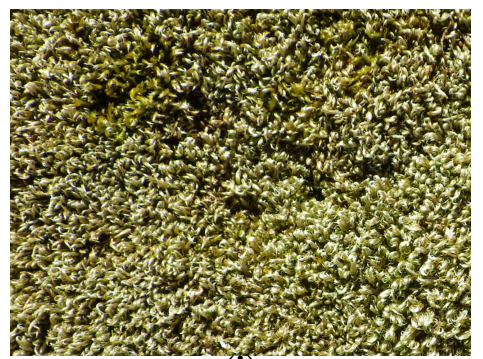

(i)

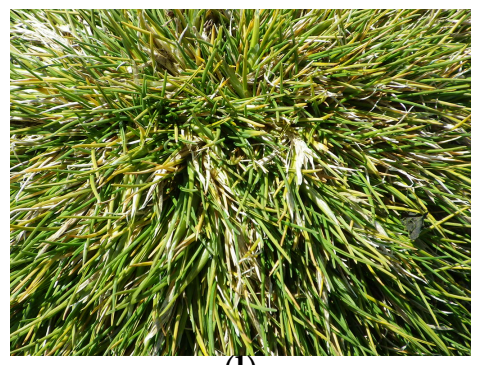

(1)

Figure 2. Vegetal classes addressed in this study: (a) crustose lichen aff. Lecanora polytropa; (b) Stereocaulon sp.; (c) Psoroma sp.; (d) Himantormia lugubris; (e) Ramalina aff. tenebrata;

(f) Usnea antarctica; (g) Xanthoria sp.; (h) Sphaerophorus globosus; (i) Sanionia uncinata; (j) Andreaea sp.;

(k) Prasiola crispa; and (1) Deschampsia antarctica.

\subsection{Discrimination between Cover Classes}

We used Linear Discriminant Analysis (LDA) in combination with Principal Component Analysis (PCA-LDA) to classify the cover classes according to their reflectance spectra [42-45]. The number of independent variables for a LDA has to be smaller than the number of samples in each class, and high-resolution spectra contain a high degree of redundancy. For these reasons we first performed a Principal Component Analysis (PCA) to reduce the large number of variables (wavelengths in this 
case) to a small number of principal components, i.e., linear combinations of the data variates that retain most of the variance between the samples. Since all the variates were expressed in the same scale and had similar amounts of variance, we based the PCA on sums of squares and products. We extracted the principal components with eigenvalues greater than one, five principal components in this study, that we used as predictor variables in the LDA. Previous to LDA, those principal components were normalized to $[0,1]$, in order to eliminate any differences of range between the variables. For the LDA, we used the stepwise method, with the Wilks' Lambda statistic as the variable selection method. At each step, the variable that minimized the overall Wilks' Lambda was entered into the discriminant equation.

We estimated the relative importance of each region of the reflectance spectrum for the discrimination among cover classes as derived from the loadings of each wavelength in each PC (according to the PC analysis), the correlations between each PC and the standardized canonical discriminant functions (according to the Structure Matrix obtained from the LDA), and the proportion of variance explained by each canonical function. The resulting index was normalized to $[0,1]$.

We produced a classification matrix in which errors of inclusion (spectra wrongly labelled as belonging to the class of interest) and errors of exclusion (spectra that belong to the class of interest but have been classified as belonging to another class) are quantified for each class. We considered the classification results with the full dataset and also by leave-one-out cross-validation. Leave-one-out cross-validation classifies each case separately using the partition derived from all cases except the one being classified, in order to account for over-fitting. Note that the purpose of our study was not the design of an optimal classifier but to assess the separability of the dataset. In consequence, the estimation of classification accuracy by a "weak" (in the sense of linear) classifier is used as an indicator of the separability of the spectra, and not as an indicator of the suitability of a given model as optimal classifier for the problem at hand. If PCA-LDA is able to adequately separate the dataset, this means that the dataset is easily separable, and therefore powerful classifiers may be able to tackle the problem when other factors enter the equation (such as spectral mixing or atmospheric influence). Leave-one-out cross-validation is not used in this context to build a generalizable classifier but to measure the robustness of our assessment with respect to over-fitting to the training dataset. We computed the kappa observer agreement index, $\kappa$, that estimates the extent to which correct values in the classification matrices are due to true agreement rather than to pure chance [46-48].

As a complementary means to obtain independent insight about the relationships among cover classes, we also mapped all the spectra to a two-dimensional manifold using a discrete Self-Organizing Map (SOM) [49-52] with size $15 \times 15$. Then, we fitted a two-dimensional Gaussian to the set of spectra of each class on the manifold, and represented them on the map. We used our own computer code, written in $\mathrm{C}++$, for the SOM, the Gaussian fit and the graphical output. Due to the topology preservation capabilities of the SOM, this is an interesting way of visualizing the relations among classes according to their spectra. In addition, this provides an alternative source of information about the potential for discrimination between classes, obtained by a methodology which is independent and fundamentally different from the PCA-LDA analysis.

\section{Results}

As shown in Figure 3, the most important region for discrimination among cover classes was in the visible and near UV (380 $\mathrm{nm}$ to $700 \mathrm{~nm}$ ), with the relative importance of spectral bands then steeply decreasing towards the NIR region, from $700 \mathrm{~nm}$ onwards, where the spectral signatures gradually converged for most classes except bare ground and Andreaea.

The alga Prasiola, the flowering plant Deschampsia and moss mats of Sanionia showed a marked red edge, with a ratio between the reflectance at $750 \mathrm{~nm}$ and at $680 \mathrm{~nm}$ varying between 3.5 to 4.8 , four to five times higher than that of bare ground. This contrasts with the weak red edge shown by lichens, especially the crustose lichen aff. Lecanora, Xanthoria, Sphaerophorus, Usnea and Himantormia, with values of the $750 \mathrm{~nm} / 680 \mathrm{~nm}$ ratio between 1.5 and 2.3 , which is $50 \%$ to $80 \%$ higher than that of 
bare ground. The lichens Psoroma and Ramalina showed more marked red edges, with values of the $750 \mathrm{~nm} / 680 \mathrm{~nm}$ ratio between 2.3 and 2.1, which is c. 2.5 times than in ground. Andreaea showed the lower ratio, but we have to keep in mind that this class appears in patches where this moss is mixed with rocks.

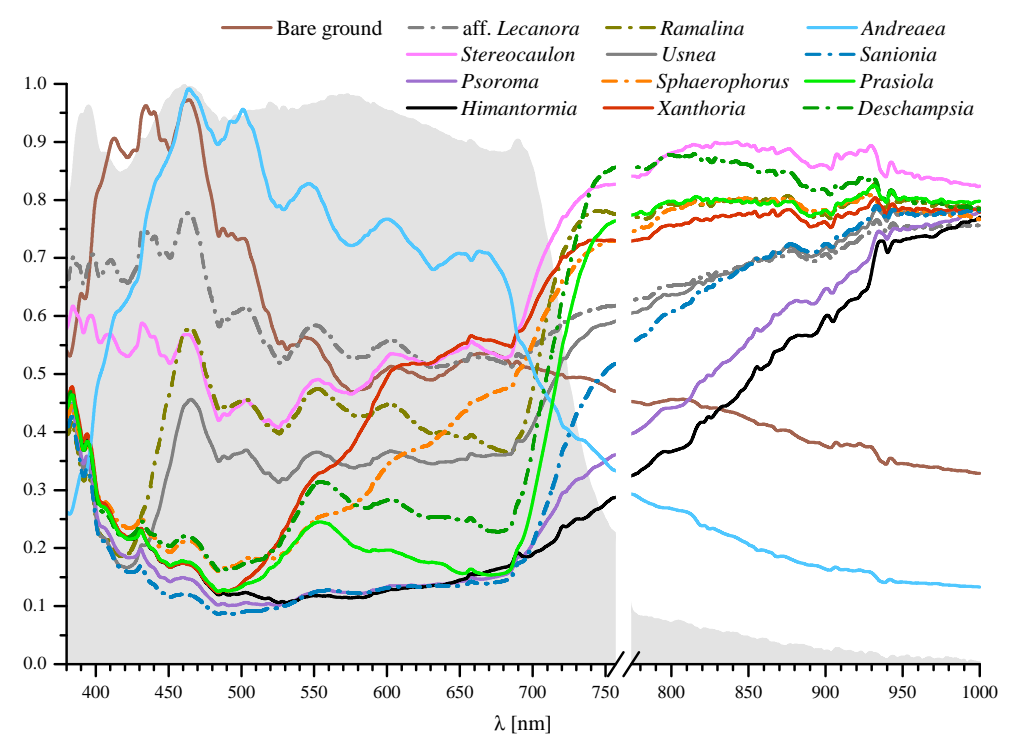

Figure 3. Average reflectance spectra of the thirteen cover classes studied. The shadowed background shows the relative importance of each wavelength for Principal Component Analysis-Linear Discriminant Analysis (PCA-LDA) discrimination among classes. The noisy 757-774 nm region was excluded.

Looking at the spectral patterns shown by different lichens, we can distinguish different types. Himantormia and Psoroma showed similar spectral patterns, with low reflectance in all the visible range, and a gradual increase from the red and near infrared regions, with a modest green edge in Psoroma. The reflectance peaks observed for other lichens at about $460 \mathrm{~nm}, 500 \mathrm{~nm}$ and $560 \mathrm{~nm}$ were lacking or very weak in these two lichens. The patterns shown by Usnea and Ramalina were similar and contrasted with those of other lichens, although the red edge was more conspicuous in Ramalina, and Usnea showed a gradual increase in reflectance in the near infrared in contrast with the nearly constant reflectance shown by Ramalina in this region. Both showed a remarkable peak at about $460 \mathrm{~nm}$, and lower peaks at $500 \mathrm{~nm}, 550 \mathrm{~nm}$ and $600 \mathrm{~nm}$. The crustose lichen aff. Lecanora and Stereocaulon can also be grouped for their distinct pattern. Both lichens showed relatively high reflectance in the near UV and violet region, in contrast with all other species, that showed a local minimum in this region at c. $415 \mathrm{~nm}$. From $450 \mathrm{~nm}$ to $680 \mathrm{~nm}$ their pattern was similar to that of other lichens such as Usnea, especially in the case of the crustose lichen. Then, Stereocaulon showed a more marked red edge than the crustose lichen, whose red edge was the most modest among the lichens studied. Sphaerophorus and Xanthoria showed rather similar patterns, with maximum absorption in the blue region and then a gradual increase in reflectance up to the near infrared region. Xanthoria is a brightly orange lichen and shows a steep increase in reflectance from the minimum observed in the blue region to the orange region, and then a modest increase in the red, with a weaker red edge than that of Sphaerophorus.

The first five principal components explained an accumulated $99.4 \%$ of the total variance, see Table 2. There were significant differences between cover classes for all PCs. All PCs added significant $(P<0.001)$ predictive power to the discriminant function. The stepwise method selected the five PCs to be added in its final step in five canonical discriminant functions. 
Table 2. Explained variance of each of the first five principal components (PC) and test of equality of group means using a Multivariate Analysis of Variance (MANOVA): Wilks' Lambda $(\Lambda)$, F-test statistic, degrees of freedom $\left(\mathrm{df}_{1,2}\right)$ and significance $(P)$.

\begin{tabular}{cccccc}
\hline PC & Variance & $\boldsymbol{\Lambda}$ & $\boldsymbol{F}$ & $\mathbf{d f}_{\mathbf{1 , 2}}$ & $\boldsymbol{P}$ \\
\hline$\# 1$ & $57.9 \%$ & 0.017 & 1826.114 & 12,377 & $<0.001$ \\
$\# 2$ & $32.5 \%$ & 0.195 & 129.428 & 12,377 & $<0.001$ \\
$\# 3$ & $4.9 \%$ & 0.089 & 322.444 & 12,377 & $<0.001$ \\
$\# 4$ & $2.5 \%$ & 0.093 & 306.053 & 12,377 & $<0.001$ \\
$\# 5$ & $1.7 \%$ & 0.068 & 431.742 & 12,377 & $<0.001$ \\
\hline
\end{tabular}

The full PCA-LDA partition resulted in $91.8 \%$ of cases being correctly classified $(\kappa=0.91)$, $91.3 \%(\kappa=0.91)$ using leave-one-out cross-validation (hit ratio 11.9 times greater than chance; Tables 3 and 4$)$.

Bare ground, the crustose lichen aff. Lecanora, Stereocaulon, Himantormia and Andreaea were the most clearly distinguishable: $100 \%$ of cases belonging to these classes were correctly identified and no cases of other classes were wrongly classified in these classes (Tables 3 and 4). In contrast, Deschampsia and Prasiola were the classes most frequently confused (mainly with each other), with $73 \%$ and $63 \%$ correct classification in the original classification (Table 3) and $70 \%$ and $60 \%$ in the cross-validated classification (Table 4). The rest of errors came from Ramalina and Usnea, which showed some degree of confusion with each other, Sanionia with Prasiola, and Sphaerophorus with Sanionia, with Xanthoria and in a lesser degree with Psoroma, but all with correct classification above $80 \%$.

Table 3. Error matrix of Principal Component Analysis-Linear Discriminant Analysis (PCA-LDA) classification of the full dataset $(n=30$ spectra per class; Overall Accuracy OA $=91.8 \%, \kappa=0.91$ ). Rows: True class; Columns: Predicted. The boldfaced values in the diagonal are the number of correctly classified samples in each class. The last two columns give the producer's and user's accuracy.

\begin{tabular}{ccccccccccccccccc}
\hline True Pred. & Bare & Crus. & Ster. & Ram. & Usn. & Psor. & Him. & Spha. & Xan. & Andr. & San. & Desc. & Pras. & Prod. & User \\
\hline Bare ground & $\mathbf{3 0}$ & 0 & 0 & 0 & 0 & 0 & 0 & 0 & 0 & 0 & 0 & 0 & 0 & $100 \%$ & $100 \%$ \\
Crus. aff. Lec. & 0 & $\mathbf{3 0}$ & 0 & 0 & 0 & 0 & 0 & 0 & 0 & 0 & 0 & 0 & 0 & $100 \%$ & $100 \%$ \\
Stereocaulon & 0 & 0 & $\mathbf{3 0}$ & 0 & 0 & 0 & 0 & 0 & 0 & 0 & 0 & 0 & 0 & $100 \%$ & $100 \%$ \\
Ramalina & 0 & 0 & 0 & $\mathbf{2 9}$ & 1 & 0 & 0 & 0 & 0 & 0 & 0 & 0 & 0 & $96.7 \%$ & $87.9 \%$ \\
Usnea & 0 & 0 & 0 & 4 & $\mathbf{2 6}$ & 0 & 0 & 0 & 0 & 0 & 0 & 0 & 0 & $86.7 \%$ & $96.3 \%$ \\
Psoroma & 0 & 0 & 0 & 0 & 0 & $\mathbf{3 0}$ & 0 & 0 & 0 & 0 & 0 & 0 & 0 & $100 \%$ & $96.8 \%$ \\
Himantormia & 0 & 0 & 0 & 0 & 0 & 0 & $\mathbf{3 0}$ & 0 & 0 & 0 & 0 & 0 & 0 & $100 \%$ & $100 \%$ \\
Sphaerophorus & 0 & 0 & 0 & 0 & 0 & 1 & 0 & $\mathbf{2 4}$ & 2 & 0 & 3 & 0 & 0 & $80.0 \%$ & $100 \%$ \\
Xanthoria & 0 & 0 & 0 & 0 & 0 & 0 & 0 & 0 & $\mathbf{3 0}$ & 0 & 0 & 0 & 0 & $100 \%$ & $93.8 \%$ \\
Andreaea & 0 & 0 & 0 & 0 & 0 & 0 & 0 & 0 & 0 & $\mathbf{3 0}$ & 0 & 0 & 0 & $100 \%$ & $100 \%$ \\
Sanionia & 0 & 0 & 0 & 0 & 0 & 0 & 0 & 0 & 0 & 0 & $\mathbf{2 8}$ & 0 & 2 & $93.3 \%$ & $82.4 \%$ \\
Deschampsia & 0 & 0 & 0 & 0 & 0 & 0 & 0 & 0 & 0 & 0 & 0 & $\mathbf{2 2}$ & 8 & $73.3 \%$ & $73.3 \%$ \\
Prasiola & 0 & 0 & 0 & 0 & 0 & 0 & 0 & 0 & 0 & 0 & 3 & 8 & $\mathbf{1 9}$ & $63.3 \%$ & $65.5 \%$ \\
\hline
\end{tabular}

The PCA-LDA results were coherent with the SOM mapping of the spectra to a 2D manifold, see Figure 4. The ellipses represent two-dimensional Gaussian fits $(\mu, \sigma)$ to the sample set of each cover class in the 2D manifold. The inherent topology-preserving nature of the SOM allows to visualize the relationships between classes. In the resulting mapping, bare ground on one corner and tightly close Deschampsia and Prasiola on the opposite "green" corner clearly represent two extremes. The other two opposite corners were occupied by the "orange" Xanthoria on one side and the Andreaea moss on the other. Close to bare ground were the crustose lichen aff. Lecanora and Stereocaulon on one side, and Himantormia and Psoroma on the other. Halfway between the Andreaea corner and the "green" corner were the lichens Ramalina and Usnea, close to each other. Last, Sphaerophorus and Sanionia were located between the "orange" corner and the "green" corner, with Sanionia midway between Prasiola and Sphaerophorus. In spite of the fundamentally different nature of the analytical procedures 
involved in PCA-LDA and in SOM mapping, all these spatial relationships derived from the SOM, regarding relative positions, proximity and neighbourhood relations, showed a good match with the PCA-LDA results in Tables 3 and 4.

Table 4. Error matrix of leave-one-out PCA-LDA classification $(n=30$ spectra per class; OA $=91.3 \%$, $\kappa=0.91)$. Rows: True class; Columns: Predicted. The boldfaced values in the diagonal are the number of correctly classified samples in each class. The last two columns give the producer's and user's accuracy.

\begin{tabular}{ccccccccccccccccc}
\hline True Pred. & Bare & Crus. & Ster. & Ram. & Usn. & Psor. & Him. & Spha. & Xan. & Andr. & San. & Desc. & Pras. & Prod. & User \\
\hline Bare ground & $\mathbf{3 0}$ & 0 & 0 & 0 & 0 & 0 & 0 & 0 & 0 & 0 & 0 & 0 & 0 & $100 \%$ & $100 \%$ \\
Crus. aff. Lec. & 0 & $\mathbf{3 0}$ & 0 & 0 & 0 & 0 & 0 & 0 & 0 & 0 & 0 & 0 & 0 & $100 \%$ & $100 \%$ \\
Stereocaulon & 0 & 0 & $\mathbf{3 0}$ & 0 & 0 & 0 & 0 & 0 & 0 & 0 & 0 & 0 & 0 & $100 \%$ & $100 \%$ \\
Ramalina & 0 & 0 & 0 & $\mathbf{2 9}$ & 1 & 0 & 0 & 0 & 0 & 0 & 0 & 0 & 0 & $96.7 \%$ & $87.9 \%$ \\
Usnea & 0 & 0 & 0 & 4 & $\mathbf{2 6}$ & 0 & 0 & 0 & 0 & 0 & 0 & 0 & 0 & $86.7 \%$ & $96.3 \%$ \\
Psoroma & 0 & 0 & 0 & 0 & 0 & $\mathbf{3 0}$ & 0 & 0 & 0 & 0 & 0 & 0 & 0 & $100 \%$ & $96.8 \%$ \\
Himantormia & 0 & 0 & 0 & 0 & 0 & 0 & $\mathbf{3 0}$ & 0 & 0 & 0 & 0 & 0 & 0 & $100 \%$ & $100 \%$ \\
Sphaerophorus & 0 & 0 & 0 & 0 & 0 & 1 & 0 & $\mathbf{2 4}$ & 2 & 0 & 3 & 0 & 0 & $80.0 \%$ & $100 \%$ \\
Xanthoria & 0 & 0 & 0 & 0 & 0 & 0 & 0 & 0 & $\mathbf{3 0}$ & 0 & 0 & 0 & 0 & $100 \%$ & $93.8 \%$ \\
Andreaea & 0 & 0 & 0 & 0 & 0 & 0 & 0 & 0 & 0 & $\mathbf{3 0}$ & 0 & 0 & 0 & $100 \%$ & $100 \%$ \\
Sanionia & 0 & 0 & 0 & 0 & 0 & 0 & 0 & 0 & 0 & 0 & $\mathbf{2 8}$ & 0 & 2 & $93.3 \%$ & $82.4 \%$ \\
Deschampsia & 0 & 0 & 0 & 0 & 0 & 0 & 0 & 0 & 0 & 0 & 0 & $\mathbf{2 1}$ & 9 & $70.0 \%$ & $70.0 \%$ \\
Prasiola & 0 & 0 & 0 & 0 & 0 & 0 & 0 & 0 & 0 & 0 & 3 & 9 & $\mathbf{1 8}$ & $60.0 \%$ & $62.1 \%$ \\
\hline
\end{tabular}

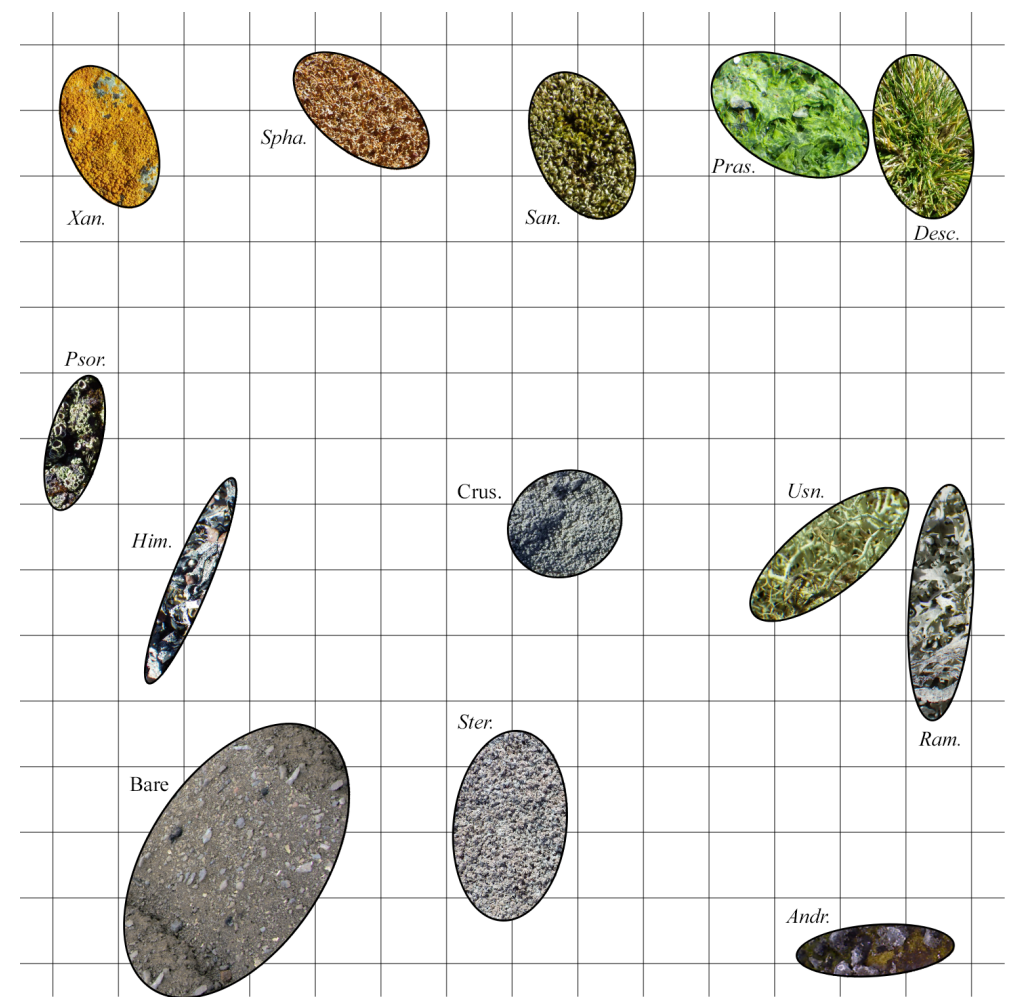

Figure 4. Gaussian fits of the cover spectra in a self-organizing mapping (SOM) to a 2D manifold. The SOM preserves the topology of the high-dimensional feature space, allowing for visualization of the relationships between cover classes.

\section{Discussion}

Our study shows that it is possible to differentiate among the representative taxa in the Antarctic vegetation using their spectra in the near ultraviolet (UV), visible and near-infrared (NIR) part of 
the spectrum. The results are encouraging in regard to the use of hyperspectral imagery to map the distribution of different vegetation types in the ice-free areas of Antarctica, which could greatly facilitate monitoring of changes along time in response to environmental changes such as global warming and increasing human disturbance. Remote sensing monitoring would allow reducing the costs and also the environmental impacts associated with field surveys.

According to our results, the spectral ranges that would optimize discrimination between vegetation elements are in the near-UV and visible region, whereas the importance of the bands decreases sharply in the NIR region. This is consistent with previous laboratory analyses of spectra of subartic lichens $[24,26,53,54]$. Note that our study also covers mosses, an alga and a vascular plant, but $60 \%$ of our target classes are lichens, in consonance with their abundance in the region, and factors allowing the separability among lichens must necessarily have significant weight in the results. Reflectance in the visible range $(400 \mathrm{~nm}$ to $700 \mathrm{~nm})$ is mostly derived from tissue pigments, while tissue cell structure and biomass determine the reflectance in the NIR region (700 $\mathrm{nm}$ to $1300 \mathrm{~nm})[55,56]$. The red edge, which was more conspicuous in the alga Prasiola, the flowering plant Deschampsia and moss mats dominated by Sanionia, is produced by the combination of the strong chlorophyll absorption in the red region and its strong reflectance in the NIR [57]. The slope of this red edge is correlated with total chlorophyll concentration and water content [55,58]. The red edge is characteristic of vascular plants and "green" vegetation in general. In fact, this characteristic is extensively used for detection of vegetation, using classical vegetation indexes (e.g., NDVI). In lichens, despite the presence of chlorophyll in the inner algal cells, this red edge is usually absent or very weak [24], which would explain the low performance of NDVI to detect vegetation in Antarctica [22,23]. This is because most lichens have other pigments in the cortex that mask the chlorophyll (e.g., melanins, that result in a nearly black thallus). The low reflectance in the visible wavelengths shown by the dark coloured lichens Psoroma and Himantormia might be an adaptation to favor the heating of the thallus in the stressful low temperature environments typical of the region (see also [24] for subarctic lichens). The green peak, increased reflectance observed in the green region (around $550 \mathrm{~nm}$ ), is also related to chlorophyll concentration, and was most conspicuous in the vascular plant Deschampsia and the alga Prasiola, but could be also observed in some of the lichens, such as Usnea, Ramalina and Stereocaulon.

Previous studies have suggested that analyses based on the spectrum of only one species of lichen would be sufficient for mapping lichen habitats in the Antarctic tundra [26], with reference to the results in [23]. Note, however, that the aim of [23] was the discrimination of rocks covered by lichens in order to avoid the influence of lichens on mineralogical studies. The authors looked for some unifying spectral trait that would allow treating several lichen species as a single target class, while at the same time maximizing the difference with exposed quartzite rock. They found a region in the SWIR range, $2.0 \mu \mathrm{m}$ to $2.4 \mu \mathrm{m}$, where the spectra of five different lichen species differed only in level but not in shape. Thus, normalization sufficed to equalize the lichen spectra in that range, in a way that would allow good discrimination of rocks covered by lichen from bare quartzite rock, taking advantage of the characteristic absorption peak of quartzite at $2.2 \mu \mathrm{m}$, not present in the lichen spectra. The aim of [26] was mapping lichen coverage in Antarctica. The authors projected pixel reflectance values of Landsat 7 and 8 onto three endmember spectra corresponding to three different lichen species after performing the SWIR-equalizing normalization suggested in [23]. Note, however, that Landsat sensors are multispectral sensors with a spectral resolution significantly lower than the spectral resolution of field spectrometers and hyperspectral sensors. Band 7 of Landsat 7 integrates the whole 2.09-2.35 $\mu \mathrm{m}$ range into a single reflectance value. The band has been narrowed a bit in Landsat 8, down to 2.11-2.29 $\mu \mathrm{m}$, but upon inspection of the normalized quartzite and lichen spectra shown in Figure 5b of [23], it is not clear that the integration of $180 \mathrm{~nm}$ ( $260 \mathrm{~nm}$ in Landsat 7$)$ could preserve the discriminant capabilities of the full resolution spectra. In addition, the authors used all Landsat bands, not only band 7 where the normalized lichen spectra are equalized. Therefore, it is plausible that the equalized SWIR values may have had less weight on their results than it may seem. The authors concluded that the spectrum of only one species of lichen would be enough for mapping 
lichens in Antarctica, but at the same time they recognized that the maps obtained with different spectra had some differences, and recommended that future work should investigate the possibility that different types of vegetation could be discriminated by their spectral differences.

The variability shown among lichens in our study suggests that knowledge about the spectral characteristics of different lichen types is important to properly identify lichen presence. In fact, there were drastic differences between some lichens in the region of the spectrum covered by our study, and no common patterns for all lichens was found. This would hinder or totally prevent detection of some lichens in detailed vegetation studies if based on the spectrum of only one lichen species. Lichens share the terrain with other vegetation types, such as mosses, algae and vascular plants. Simplified generalizations of the findings in [23] can lead to important biases when mapping the cover of different vegetation classes. Our study assesses the simultaneous separability of all these vegetation types, and shows a mosaic of separable classes in which classes at the extremes may be easily separable (e.g., bare soil from the vascular plant Deschampsia), but all classes can be found mixed with each other on the terrain in a mixture where some of the classes may act as intermediate links of blurring agents if a simple solution for the discrimination of just the most different classes is chosen (e.g., NDVI). Our results suggest that in order to increase the accuracy and reliability of detailed vegetation mapping in Antarctica, the spectral characteristics of all representative taxa in the region must be taken into account.

In addition, the changing environmental conditions in relation to climate warming and to increasing human presence in the Antarctic is expected to cause changes in vegetation distribution patterns, with contrasting responses being expected for different taxa, both in magnitude (sensitivity to changes) and direction (some might expand while others might retreat). Changes in vegetation can occur at very short-term scales, for instance due to trampling by humans [59] or indigenous animals (e.g., seals [60]), or at longer time scales, for instance due to climate change and glacial and permafrost retreat $[6,29,61]$. Reliable detailed mapping of different vegetation classes is important for monitoring changes in distribution at these time scales. A large number of bands and high spectral resolutions are needed for detailed discrimination, such as those provided by hyperspectral imagery.

Technical development and miniaturization of hyperspectral sensors are making imaging spectrometry more accessible at lower costs. Airborne imaging spectrometers on board light aircraft can significantly reduce the costs of acquisition, facilitating a more continuous monitoring of the distribution of vegetation communities [31]. This is especially welcomed in Antarctica, where remoteness and harsh conditions in the field make remote sensing techniques especially advantageous. In this respect, the recent availability of hyperspectral sensors for low-cost unmanned aerial vehicles (UAVs) represents a major turning point for environmental research in general and for operational monitoring in the relatively small ice-free areas of Maritime Antarctica in particular. We have just shown that the spectral traits of the vegetation of Barton Peninsula could allow detailed vegetation mapping with a Visible Near Infra-Red (VNIR) hyperspectral sensor flying at low altitude and high spatial resolution, at least in what respects spectral separability. Spectral mixture, rugged topography, low sun, and rapidly changing extreme weather conditions are surmountable challenges that must be tackled in order to build a successful operational unmanned aerial system for long-term detailed vegetation monitoring in the region.

\section{Conclusions}

Our study shows that the most common vegetation taxa in ice-free areas of Antarctica can be distinguished by their reflectance spectra at ground level in the near-UV, visible and NIR parts of the spectrum. Wavelengths below $750 \mathrm{~nm}$ are the most relevant for simultaneous discrimination among all these taxa. This is the first study addressing simultaneously the spectral separability of several species of lichens and mosses, an alga and a vascular plant. This is relevant because all these types of vegetation tend to appear mixed in the region, and studies targeting just one or a few types will be hindered by the inevitable presence of other vegetation types with intermediate spectral characteristics. This study 
provides a useful baseline for future studies aiming at developing instrumentation and/or designing operational missions to monitor detailed vegetation changes in Maritime Antarctica. Upscaling to the airborne or spatial sensor level, requiring a surface model, a spatial distribution model and a radiative transfer model, can help in this aim. Alternatively, high-resolution VNIR hyperspectral sensors on board low altitude, low speed UAVs can provide experimental data to test robust spectral unmixing approaches using field spectrometry endmembers.

Acknowledgments: This research was supported by project HISURF (PROPOLAR/FCT—Portugal) and AtlantTIC (University of Vigo). We are indebted to the Korean Polar Research Institute (KOPRI) for welcoming us to their research station King Sejong at Barton Peninsula. We are very grateful to all researchers and staff of the station for their unfaltering kindness and professionalism. We also thank the Chilean Antarctic Institute (INACH) for support at Professor Julio Escudero Station (Fildes Peninsula), and for logistics in the transfers between Sandy Point (Chile) and Antarctica. Special thanks are due to Soon Gyu Hong and Young-Jun Yoon (KOPRI) for advice on vegetation distribution and for identification of lichens and mosses, and to Gonçalo Vieira and Pedro Pina (PROPOLAR) for the logistics, support and motivation.

Author Contributions: M.C.-C. and J.M.-H. conceived and designed the experiments; M.C.-C. and J.M.-H. performed the field work; J.M.-H. designed custom field spectrometry hardware and software, and analytical software; M.C.-C. analyzed the data; M.C.-C. wrote the paper and J.M.-H. contributed to writing the paper.

Conflicts of Interest: The authors declare no conflict of interest. The funding sponsors had no role in the design of the study; in the collection, analyses, or interpretation of data; in the writing of the manuscript, and in the decision to publish the results.

\section{References}

1. Turner, J.; Barrand, N.E.; Bracegirdle, T.J.; Convey, P.; Hodgson, D.A.; Jarvis, M.; Jenkins, A.; Marshall, G.; Meredith, M.P.; Roscoe, H.; et al. Antarctic climate change and the environment: An update. Polar Rec. 2014, 50, 237-259.

2. Hughes, K.A.; Convey, P. Determining the native/non-native status of newly discovered terrestrial and freshwater species in Antarctica-Current knowledge, methodology and management action. J. Environ. Manag. 2012, 93, 52-66.

3. Hughes, K.A.; Pertierra, L.R.; Molina-Montenegro, M.A.; Convey, P. Biological invasions in terrestrial Antarctica: What is the current status and can we respond? Biodivers. Conserv. 2015, 24, 1031-1055.

4. Tin, T.; Fleming, Z.L.; Hughes, K.A.; Ainley, D.G.; Convey, P.; Moreno, C.A.; Pfeiffer, S.; Scott, J.; Snape, I. Impacts of local human activities on the Antarctic environment. Antarct. Sci. 2009, 21, 3-33.

5. Turner, J.; Bindschadler, R.; Convey, P.; di Prisco, G.; Fahrbach, E.; Gutt, J.; Hodgson, D.; Mayewski, P.; Summerhayes, C. (Eds.) Antarctic Climate Change and the Environment; Scientific Committee on Antarctic Research: Cambridge, UK, 2009.

6. Favero-Longo, S.E.; Worland, M.R.; Convey, P.; Smith, R.I.L.; Piervittori, R.; Guglielmin, M.; Cannone, N. Primary succession of lichen and bryophyte communities following glacial recession on Signy Island, South Orkney Islands, Maritime Antarctic. Antarct. Sci. 2012, 24, 323-336.

7. Boy, J.; Godoy, R.; Shibistova, O.; Boy, D.; McCulloch, R.; de la Fuente, A.A.; Morales, M.A.; Mikutta, R.; Guggenberger, G. Successional patterns along soil development gradients formed by glacier retreat in the Maritime Antarctic, King George Island. Rev. Chil. Hist. Nat. 2016, 89, 6.

8. Gerighausen, U.; Brautigam, K.; Mustafa, O.; Peter, H.U. Expansion of vascular plants on an Antarctic island a consequence of climate change? In Antarctic Biology in a Global Context; Blackhuys Publishers: Leiden, The Netherlands, 2003; pp. 79-83.

9. Convey, P.; Hopkins, D.W.; Roberts, S.J.; Tyler, A.N. Global southern limit of flowering plants and moss peat accumulation. Polar Res. 2011, 30, 157-171.

10. Frenot, Y.; Chown, S.L.; Whinam, J.; Selkirk, P.M.; Convey, P.; Skotnicki, M.; Bergstrom, D.M. Biological invasions in the Antarctic: Extent, impacts and implications. Biol. Rev. 2005, 80, 45-72.

11. Kennedy, A.D. Antarctic terrestrial ecosystem response to global environmental-change. Annu. Rev. Ecol. Syst. 1995, 26, 683-704.

12. Convey, P. Maritime antarctic climate change: Signals from terrestrial biology. In Antarctic Peninsula Climate Variability: Historical and Palaeo-Environmental Perspectives; Antarctic Research Series, American Geophysical Union: Washington, DC, USA, 2003; Volume 79, pp. 145-158. 
13. Callaghan, T.V.; Jonasson, S. Arctic terrestrial ecosystems and environmental-change. Philos. Trans. R. Soc. Lond. A Math. Phys. Eng. Sci. 1995, 352, 259-276.

14. Freckman, D.W.; Virginia, R.A. Low-diversity Antarctic soil nematode communities: Distribution and response to disturbance. Ecology 1997, 78, 363-369.

15. Smith, R.I.L. Vascular plants as bioindicators of regional warming in Antarctica. Oecologia 1994, 99, 322-328.

16. Green, T.G.A.; Sancho, L.G.; Pintado, A.; Schroeter, B. Functional and spatial pressures on terrestrial vegetation in Antarctica forced by global warming. Polar Biol. 2011, 34, 1643-1656.

17. Vieira, G.; Mora, C.; Pina, P.; Schaefer, C.E.R. A proxy for snow cover and winter ground surface cooling: Mapping Usnea sp communities using high-resolution remote sensing imagery (Maritime Antarctica). Geomorphology 2014, 225, 69-75.

18. Schmidt, K.S.; Skidmore, A.K. Spectral discrimination of vegetation types in a coastal wetland. Remote Sens. Environ. 2003, 85, 92-108.

19. Mendez-Rial, R.; Calvino-Cancela, M.; Martin-Herrero, J. Accurate implementation of anisotropic diffusion in the hypercube. IEEE Geosci. Remote Sens. Lett. 2010, 7, 870-874.

20. Mendez-Rial, R.; Calvino-Cancela, M.; Martin-Herrero, J. Anisotropic Inpainting of the Hypercube. IEEE Geosci. Remote Sens. Lett. 2012, 9, 214-218.

21. Buchhorn, M.; Walker, D.A.; Heim, B.; Raynolds, M.K.; Epstein, H.E.; Schwieder, M. Ground-based hyperspectral characterization of Alaska Tundra vegetation along environmental gradients. Remote Sens. 2013, 5, 3971-4005.

22. Fretwell, P.T.; Convey, P.; Fleming, A.H.; Peat, H.J.; Hughes, K.A. Detecting and mapping vegetation distribution on the Antarctic Peninsula from remote sensing data. Polar Biol. 2011, 34, 273-281.

23. Casanovas, P.; Black, M.; Fretwell, P.; Convey, P. Mapping lichen distribution on the Antarctic Peninsula using remote sensing, lichen spectra and photographic documentation by citizen scientists. Polar Res. 2015, 34, 25633.

24. Petzold, D.E.; Goward, S.N. Reflectance spectra of subarctic lichens. Remote Sens. Environ. 1988, $24,481-492$.

25. Shin, J.; Kim, H.; Kim, S.; Hong, S. Vegetation abundance on the Barton Peninsula, Antarctica: Estimation from high-resolution satellite images. Polar Biol. 2014, 37, 1579-1588.

26. Zhang, J.; Rivard, B.; Sánchez-Azofeifa, A. Spectral unmixing of normalized reflectance data for the deconvolution of lichen and rock mixtures. Remote Sens. Environ. 2005, 95, 57-66.

27. Margules, C.R.; Pressey, R.L. Systematic conservation planning. Nature 2000, 405, 243-253.

28. Chown, S.L.; Convey, P. Spatial and temporal variability across life's hierarchies in the terrestrial Antarctic. Philos. Trans. R. Soc. Lond. B Biol. Sci. 2007, 362, 2307-2331.

29. Guglielmin, M.; Vieira, G. Permafrost and periglacial research in Antarctica: New results and perspectives. Geomorphology 2014, 225, 1-3.

30. Verhoef, W.; Bach, H. Simulation of hyperspectral and directional radiance images using coupled biophysical and atmospheric radiative transfer models. Remote Sens. Environ. 2003, 87, 23-41.

31. Calvino-Cancela, M.; Mendez-Rial, R.; Reguera-Salgado, J.; Martin-Herrero, J. Alien Plant Monitoring with Ultralight Airborne Imaging Spectroscopy. PLoS ONE 2014, 9, e102381.

32. Adams, J.; Smith, M.; Gillespie, A. Imaging Spectroscopy: Interpretation Based on Spectral Mixture Analysis; Cambridge University Press: New York, NY, USA, 1993.

33. Clasen, A.; Somers, B.; Pipkins, K.; Tits, L.; Segl, K.; Brell, M.; Kleinschmit, B.; Spengler, D.; Lausch, A.; Foerster, M. Spectral unmixing of forest crown Ccomponents at close range, airborne and simulated sentinel-2 and EnMAP spectral imaging scale. Remote Sens. 2015, 7, 15361-15387.

34. Lee, B.; Won, Y.; Oh, S. Meteorological Characteristics at King Sejong Station, Antarctica (1988-1996); Report BSPE 97604-00-1020-7; Korea Ocean and Developmental Institute: Ansan, Korea, 1997;pp. 571-599.

35. Chung, H.; Kim, J.H.; Lee, B.Y.; Keun, C.S.; Kim, Y. Ice cliff retreat and sea-ice formation observed around King Sejong Station in King George Island, West Antarctica. Ocean Polar Res. 2004, 26, 1-10.

36. Kim, J.H.; Ahn, I.Y.; Hong, S.G.; Andreev, M.; Lim, K.M.; Oh, M.J.; Koh, Y.J.; Hur, J.S. Lichen flora around the Korean Antarctic Scientific Station, King George Island, Antarctic. J. Microbiol. 2006, 44, 480-491.

37. Kim, J.H.; Ahn, I.Y.; Lee, K.S.; Chung, H.; Choi, H.G. Vegetation of Barton Peninsula in the neighbourhood of King Sejong Station (King George Island, Maritime Antarctic). Polar Biol. 2007, 30, 903-916.

38. Kiedron, P.; Berndt, J.; Michalsky, J.; Harrison, L. Column water vapor from diffuse irradiance. Geophys. Res. Lett. 2003, 30, 1565. 
39. Øvstedal, D.; Lewis Smith, R. Lichens of Antarctica and South Georgia: A Guide to Their Identification and Ecology; Cambridge University Press: Cambridge, UK, 2001.

40. Ochyra, R.; Lewis Smith, R.; Bednarek-Ochyra, H. The Illustrated Moss Flora of Antarctica; Cambridge University Press: Cambridge, UK, 2008.

41. Lee, Y.I.; Lim, H.S.; Yoon, H.I. Geochemistry of soils of King George Island, South Shetland Islands, West Antarctica: Implications for pedogenesis in cold polar regions. Geochim. Cosmochim. Acta 2004, $68,4319-4333$.

42. Ferreiro-Arman, M.; Da Costa, J.P.; Homayouni, S.; Martín-Herrero, J. Hyperspectral Image Analysis for Precision Viticulture. In Image Analysis and Recognition, Part II; Lecture Notes in Computer Science; Campilho, A., Kamel, M., Eds.; Springer: Berlin/Heidelberg, Germany, 2006; Volume 4142, pp. 730-741.

43. Song, S.; Gong, W.; Zhu, B.; Huang, X. Wavelength selection and spectral discrimination for paddy rice, with laboratory measurements of hyperspectral leaf reflectance. ISPRS J. Photogramm. Remote Sens. 2011, 66, 672-682.

44. Asner, G.P.; Martin, R.E.; Bin Suhaili, A. Sources of canopy chemical and spectral diversity in Lowland Bornean Forest. Ecosystems 2012, 15, 504-517.

45. Lehmann, J.R.K.; Grosse-Stoltenberg, A.; Roemer, M.; Oldeland, J. Field Spectroscopy in the VNIR-SWIR Region to discriminate between mediterranean native plants and exotic-invasive Shrubs based onleaf tannin Content. Remote Sens. 2015, 7, 1225-1241.

46. Cohen, J. A Coefficient of Agreement for nominal scales. Educ. Psychol. Meas. 1960, 20, 37-46.

47. Landis, J.R.; Koch, G.G. Measurement of observer agreement for categorical data. Biometrics 1977, 33, $159-174$.

48. Congalton, R.G.; Oderwald, R.G.; Mead, R.A. Assessing Landsat classification accuracy using discrete multivariate statistical techniques. Photogramm. Eng. Remote Sens. 1983, 49, 1671-1678.

49. Kohonen, T. Self-organized formation of topologically correct feature maps. Biol. Cybern. 1982, 43, 59-69.

50. Kohonen, T. The self-organizing map. Proc. IEEE 1990, 78, 1464-1480.

51. Martín-Herrero, J.; Ferreiro-Arman, M.; Alba-Castro, J. Grading textured surfaces with automated soft clustering in a supervised SOM. In Image Analysis and Recognition, Part II; Lecture Notes in Computer Science; Campilho, A., Kamel, M., Eds.; Springer: Berlin/Heidelberg, Germany, 2004; Volume 3212, pp. 323-330.

52. Aymerich, I.F.; Oliva, M.; Giralt, S.; Martín-Herrero, J. Detection of Tephra Layers in Antarctic Sediment Cores with Hyperspectral Imaging. PLoS ONE 2016, 11, e0146578.

53. Bechtel, R.; Rivard, B.; Sánchez-Azofeifa, A. Spectral properties of foliose and crustose lichens based on laboratory experiments. Remote Sens. Environ. 2002, 82, 389-396.

54. Rees, W.; Tutubalina, O.; Golubeva, E. Reflectance spectra of subarctic lichens between 400 and $2400 \mathrm{~nm}$. Remote Sens. Environ. 2004, 90, 281-292.

55. Tucker, C.J. Red and photographic infrared linear combinations for monitoring vegetation. Remote Sens. Environ. 1979, 8, 127-150.

56. Ceccato, P.; Flasse, S.; Tarantola, S.; Jacquemoud, S.; Gregoire, J.M. Detecting vegetation leaf water content using reflectance in the optical domain. Remote Sens. Environ. 2001, 77, 22-33.

57. Ayala-Silva, T.; Beyl, C.A. Changes in spectral reflectance of wheat leaves in response to specific macronutrient deficiency. Adv. Space Res. 2005, 35, 305-317.

58. Liu, L.Y.; Wang, J.H.; Huang, W.J.; Zhao, C.J.; Zhang, B.; Tong, Q.X. Estimating winter wheat plant water content using red edge parameters. Int. J. Remote Sens. 2004, 25, 3331-3342.

59. Pertierra, L.R.; Lara, F.; Tejedo, P.; Quesada, A.; Benayas, J. Rapid denudation processes in cryptogamic communities from Maritime Antarctica subjected to human trampling. Antarct. Sci. 2013, 25, 318-328.

60. Favero-Longo, S.E.; Cannone, N.; Worland, M.R.; Convey, P.; Piervittori, R.; Guglielmin, M. Changes in lichen diversity and community structure with fur seal population increase on Signy Island, South Orkney Islands. Antarct. Sci. 2011, 23, 65-77.

61. Sancho, L.G.; Valladares, F. Lichen colonization of recent moraines on Livingston Island (South Shetland, Antarctica). Polar Biol. 1993, 13, 227-233.

(C) 2016 by the authors; licensee MDPI, Basel, Switzerland. This article is an open access article distributed under the terms and conditions of the Creative Commons Attribution (CC-BY) license (http://creativecommons.org/licenses/by/4.0/). 